Disponível em

http://www.anpad.org.br/rac

RAC, Rio de Janeiro, v. 19, $2^{\text {a }}$ Edição Especial, art. 6, pp. 221-244, Agosto 2015

http://dx.doi.org/10.1590/1982-7849rac20151840

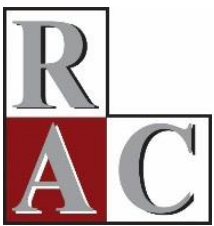

\title{
Impacto do Sistema de Controle sobre a Venda de Novos Produtos
}

\author{
Impact of Control Systems over New Product Sales
}

Valter Afonso Vieira

Universidade Estadual de Maringá - UEM

Juliano Domingues Silva

Universidade Estadual de Maringá - UEM

Sean Cassiolato Berbert Pontifícia Universidade Católica do Paraná - PUCPR

Valter da Silva Faia Universidade Estadual de Maringá - UEM 


\title{
Resumo
}

Este artigo busca compreender o impacto do sistema de controle do vendedor na relação entre esforço de vendas e desempenho. Duas perspectivas de sistema de controle são adotadas: resultado e comportamento. A diferença entre ambas se dá na forma como o vendedor é avaliado para realizar seu trabalho. Se o gerente de vendas se preocupa apenas com o resultado final das vendas, adota-se um sistema de controle baseado em resultados. Entretanto, se o gerente se preocupa com a capacidade, a habilidade e o conhecimento que o vendedor possui, adota-se um sistema de controle baseado no comportamento. Com base na teoria de Anderson e Oliver (1987) e Oliver e Anderson (1994), sugere-se um modelo teórico para explicar desempenho com vendas, posicionando sistema de controle como variável moderadora. Duas pesquisas descritivas de campo são realizadas para testar as hipóteses do modelo proposto com vendedores de medicamentos e de automóveis. Quatro modelos de regressão são aplicados e analisados. A primeira conclusão é que a percepção da inovação do produto pelo vendedor realmente interfere no lançamento de novos produtos. A segunda demonstrou que o esforço do vendedor tem uma relação negativa com o desempenho da farmácia. A terceira é a constatação do efeito moderador do sistema de controle na relação entre experiência do vendedor e seu esforço com vendas.

Palavras-chave: sistema; controle; vendas; marketing; desempenho.

\begin{abstract}
This paper's main goal is to understand the impact of control systems on the relationship between a salesperson's effort and their performance. The control systems have two perspectives: outcome and behavior. The difference between them is how a salesperson is evaluated in regards to their job. If the sales manager is only concerned with sales results, the control system is based on outcome. However, if the sales manager is concerned with a salesperson's capacities, abilities and knowledge, the control system is based on behavior. Based on the theories developed by Anderson and Oliver (1987) and Oliver and Anderson (1994), we proposed a theoretical framework to explain sales performance, positioning the control system as a moderating variable. We undertook two descriptive field investigations to test the proposed model's hypotheses for pharmaceutical sales representatives and car dealer salespersons. We estimated four regression equations to test the hypotheses. The first conclusion is that the perception of product innovation by salespeople actually influences the launch of new products. The second conclusion showed that salesperson effort has a negative relationship with performance. Third, we demonstrated the moderating effect control systems have on the relationship between salesperson experience and sales efforts.
\end{abstract}

Key words: system; control; sales; marketing; performance. 


\section{Introdução}

A pesquisa e o desenvolvimento de novos produtos é uma área que ganha cada vez mais espaço no ambiente competitivo e globalizado. Para Cohen, Eliashberg e Ho (1997), a capacidade de uma empresa lançar novos produtos com sucesso é fundamental para o crescimento e para a sobrevivência da indústria. Nesse contexto, a introdução dos novos produtos no mercado se torna um dos motores para o sucesso empresarial, fazendo com que as empresas invistam recursos substanciais em pesquisa, desenvolvimento, fabricação, design e comercialização das novas soluções.

Além da inovação, uma parte do sucesso das vendas dos novos produtos é decorrente de quão bem a força de vendas vai gerenciar o novo produto (Ahearne, Rapp, Hughes, \& Jindal, 2010). De fato, a inovação por si só pode não ser um determinante para vender o produto. Na cadeia de distribuição dos novos produtos, o vendedor desempenha um papel fundamental por estar nas linhas das fronteiras entre o produto inovador, a indústria e o cliente. Assim, o desempenho dos novos produtos pode estar condicionado à forma como o vendedor percebe, compreende e se esforça para vender o produto inovador, sem ponderar também os aspectos de liderança organizacional (Ahearne, Mathieu, \& Rapp, 2005) ou de times de vendas (Ahearne, Mackenzie, Podsakoff, Mathieu, \& Lam, 2010).

Alguns trabalhos mostram que a falta de comprometimento do vendedor com o novo produto é um fator que contribui para explicar a baixa taxa de sucesso das vendas deste novo produto (AtuaheneGima, 1997; Basu, Lal, Srinivasan, \& Staelin, 1985; Fu, Jones, \& Bolander, 2008). Especificamente, a falta de comprometimento do vendedor pode ser devido aos seguintes fatores: primeiro, a possibilidade de vender menos o novo produto por ganhar uma baixa comissão, preferindo vender o produto tradicional (Fang, Evans, \& Landry, 2005; Mallin \& Pullins, 2009); segundo, a necessidade de se esforçar mais para argumentar a inovação, podendo gerar estresse; terceiro, a dificuldade dos consumidores compreenderem o produto como um potencial substituto para o antigo; quarto, a possibilidade de o novo produto gerar um pouco de dúvida pelo vendedor ou pela percepção do cliente, dificultando a venda.

A falta de comprometimento do vendedor pode ser melhorada se houver sistemas de controle definidos e claros. Hultink e Atuahene-Gima (2000) comentam que determinadas organizações falham em não compreender como implementar e gerenciar sistemas de resultados que alavanquem o desempenho da firma. Alguns sistemas de controle por resultados estão associados a benefícios, bonificações, prêmios, salários adicionais, viagens, etc. Outros sistemas de controle por comportamento estão condicionados à realização das atividades, das normas e dos controles diários do vendedor.

Miao e Evans (2014) mostraram que o sistema de controle por resultado, por capacidade individual e por atividade diária e suas respectivas interações influenciaram o prazer dos colaboradores em realizar tarefas e buscar reconhecimento. Ahearne, Mackenzie, Podsakoff, Mathieu e Lam (2010) constataram que, quando o vendedor percebe um produto como inovação, o controle por comportamento do vendedor gera um esforço menor nas vendas. Portanto, nota-se que o controle interfere na capacidade de geração de resultados da organização.

Dois sistemas de controle são relevantes no processo de atingir os resultados organizacionais: o controle por comportamento e o controle por resultado (Anderson \& Oliver, 1987). Acredita-se que, quando o sistema de controle é por resultado, a percepção da qualidade da inovação gera impacto positivo no esforço. Contrariamente, quando o sistema de controle é por comportamento, a percepção da qualidade da inovação gera impacto negativo no esforço (Ahearne, Rapp et al., 2010). Diante dessa suposição, este artigo busca compreender o papel moderador do sistema controle do vendedor na relação entre esforço de vendas, percepção de qualidade da inovação e desempenho da organização e da venda do produto. $\mathrm{O}$ foco da análise das duas investigações recai sobre produtos inovadores já lançados no mercado. O primeiro estudo é feito com vendedores de um medicamento inovador na época. $\mathrm{O}$ desempenho é a percepção de quão bem está a venda. O segundo estudo é realizado com vendedores de um automóvel inovador. O desempenho é a percepção de quão está a venda do produto inovador em específico.

RAC, Rio de Janeiro, v. 19, 2ª Edição Especial, art. 6, pp. 221-244, Agosto 2015 www.anpad.org.br/rac (oc) 
Algumas contribuições são destacadas. Inicialmente, o trabalho de Ahearne, Rapp, Hughes e Jindal (2010) especula filosoficamente o papel moderador do sistema de controle na relação entre a experiência e a percepção da qualidade inovação, mas não encontra efeito expressivo. Neste trabalho, identificou-se que o sistema de controle modera a relação entre experiência e desempenho global, entre experiência e desempenho de produto e entre experiência e esforço com vendas. A direção dos gráficos e os achados da análise de regressão apontam que o controle por comportamento ( $v s$. por resultado) tem relação mais forte (vs. fraca) com as variáveis dependentes. Segundo, o trabalho confirma o papel moderador do sistema de controle na relação entre a percepção da qualidade da inovação e o esforço com vendas. Portanto, os vendedores se esforçam aparentemente menos quando o sistema de controle é por resultado e não por comportamento, para vender um automóvel recém-lançado.

Após esta introdução, a próxima parte apresenta as hipóteses e o modelo teórico conceitual. Posteriormente, duas surveys são feitas com vendedores, sendo uma com vendedores de balcões de farmácias e outra com vendedores de concessionárias de veículos. As análises são realizadas por meio dos modelos de regressão e de interação disponíveis na syntax do PROCESS (Hayes, 2013). Por fim, os achados principais são discutidos.

\section{Sistema de Controle}

Estudos sobre controle são recorrentes na literatura sobre organizações. Martins (2006) argumenta que pesquisas sobre controle podem caminhar para duas perspectivas distintas. A primeira tem cunho funcionalista, com foco em aspectos de coordenação e função do controle em relação à organização. A segunda direciona para uma perspectiva crítica, com o propósito de explicitar as contradições sociais presentes na discussão sobre o controle. Esta pesquisa concebe o controle a partir da perspectiva organizacional funcionalista, pois compreende o controle como um mecanismo que procura assegurar a cooperação e o direcionamento dos membros de uma organização (Martins, 2006).

Desse modo, considerando a importância do papel do vendedor para o sucesso dos novos produtos, conhecer fatores que interferem no seu esforço é importante para os gerentes. Diante disso, as empresas procuram implantar estratégias para controlar, motivar e recompensar seus vendedores dado um determinado desempenho. Nesse contexto, a literatura de marketing vem intensificando as pesquisas inerentes aos sistemas de controles (Miao \& Evans, 2012, 2013, 2014). Os sistemas de controle de vendas são as políticas formais (Kuster \& Canales, 2011), regras e procedimentos empregados por organizações para influenciar e direcionar a motivação (Miao, Lund, \& Evans, 2009) e o comportamento para os resultados de vendas (Anderson \& Oliver, 1987; Miao, Evans, \& Zou, 2007).

Há dois tipos de sistema de controle de vendas: controle por comportamento e controle por resultado (Anderson \& Oliver, 1987; Oliver \& Anderson, 1994; Onyemah \& Anderson, 2009). A diferença entre ambos se dá na forma como o vendedor é avaliado para realizar seu trabalho. Se o gerente de vendas se preocupa apenas com o resultado final das vendas, ou seja, os outputs do sistema, adota-se uma forma de controle baseada em resultados. Entretanto, se o gerente se preocupa com a capacidade, a habilidade e o conhecimento que o vendedor possui, ou seja, os inputs do sistema, adota-se um sistema de controle baseado no comportamento (Anderson \& Oliver, 1987).

Anderson e Oliver (1987) fizeram a proposta de dois sistemas estratégicos de controle e os colocaram como pontos finais em um sistema de continuиm. O sistema de controle de resultado envolve pouco monitoramento da conduta do vendedor, menor supervisão pelo gerente e menor esforço para gerenciar o vendedor. Por outro lado, o sistema de controle por comportamento é o monitoramento de atividades, procedimentos e condutas tão bem quanto de resultados, no qual há altos níveis de intervenção nas atividades e métodos mais complexos de avaliação do desempenho. O modelo de Anderson e Oliver (1987) é estruturado na Tabela 1. 
Tabela 1

\section{Controle por Comportamento e Controle por Resultado}

\begin{tabular}{ll}
\hline Controle do comportamento & Controle do Resultado \\
\hline Mais estruturado & Pouco estruturado \\
Compensação fixa (salário) & Compensação variável (comissões, bônus) \\
Gestor monitora o comportamento mais do que o & $\begin{array}{l}\text { Gestor monitora o resultado mais do que o } \\
\text { comportamento }\end{array}$ \\
Muitado supervisão e muitos gestores & Pouca supervisão e poucos gestores \\
Muito contato com o gestor & Pouco contato com o gestor \\
Muito relatório e documentos (papelada) & Pouco relatório \\
Desempenho avaliado subjetivamente & Desempenho observado em poucos resultados \\
& observáveis \\
Risco maior é da firma & Risco maior é do vendedor \\
\hline
\end{tabular}

Nota. Fonte: Anderson, E., \& Oliver, R. L. (1987). Perspectives on behavior-based versus outcome-based salesforce control systems. Journal of Marketing, 51(4), 76-88. doi: 10.2307/1251249

O sistema de controle por resultado utiliza incentivos e comissões para recompensar os vendedores com base no resultado de vendas com menor envolvimento do gerente no processo de venda (Miao \& Evans, 2014). Em contraste, o sistema de controle por comportamento requer um envolvimento mais ativo entre gerente e vendedor. Nesse caso, há treinamento, avaliação e recompensa das vendas de acordo com os inputs dirigidos ao vendedor pela empresa (ex. número de novos clientes visitados), ao invés de simplesmente concentrar-se em outputs de vendas (ex.: cota de vendas) (Miao \& Evans, 2012, 2013).

Parte-se da premissa que é possível determinadas organizações adotarem os sistemas de controle de forma conjunta, levando, ao extremo, ambas as políticas de remuneração e controle de venda. Essa posição é reforçada por Oliver e Anderson (1995) e Onyemah e Anderson (2009), que testaram empiricamente um sistema de controle de vendas no formato híbrido. Oliver e Anderson (1995) realizaram análise de cluster e evidenciaram três grupos distintos de sistemas adotados pelas empresas. No primeiro grupo, os autores encontram as empresas voltadas para políticas que privilegiam o controle do comportamento; no segundo grupo, estão as empresas que adotam medidas objetivas ligadas ao resultado; e, por fim, no terceiro grupo, estão as empresas que adotam as duas filosofias em simultâneo. Onyemah e Anderson (2009) argumentaram que o sistema de controle no formato híbrido é proveniente de uma incongruência nas políticas de gestão de vendas, que podem acarretar menores níveis de desempenho do vendedor. Após essa discussão sobre o sistema de controle, a próxima etapa discute as hipóteses do trabalho.

\section{Hipóteses}

A percepção sobre o novo produto muitas vezes está ligada às crenças e aos comportamentos que o vendedor possui e, por isso, a impressão sobre o valor de um novo produto é formada com base nas informações que a empresa oferece e na sua própria compreensão do mercado (Ahearne, Rapp et al., 2010). Nesse contexto, o papel da força de vendas se torna primordial para que os novos produtos tenham melhor desempenho no mercado. Assim, a percepção do vendedor sobre o novo produto é medida pela perspectiva de quão relevante o vendedor acredita que o novo produto é benéfico, inovador e desejável para os consumidores em relação aos produtos concorrentes (Ahearne, Rapp et al., 2010; Carson, 2007). Essa percepção pode influenciar o nível do esforço do vendedor para vender esse produto. De modo 
geral, o potencial de valor agregado e de receptividade de mercado que o vendedor percebe em relação ao novo produto deve afetar seu nível de ânimo e comprometimento para vendê-lo. Isto ocorre devido à necessidade frequente do vendedor alocar esforço dentro da carteira de produto (Ahearne, Rapp et al., 2010; Rangaswamy, Sinha, \& Zoltners, 1990).

No que diz respeito à percepção do novo produto pelo vendedor em relação ao esforço, a literatura atual levanta duas posições. A primeira sugere que os vendedores se esforçarão mais se acreditarem no potencial de mercado e no valor do produto, aproveitando a capacidade de venda. Tem-se, portanto, uma relação positiva entre esforço e desempenho. A segunda visão sugere um efeito oposto: as fontes externas complementares de marketing do novo produto, como publicidade, patrocínios, marketing boca a boca etc., podem levar o vendedor a acreditar na superioridade desse novo produto (Eisenhardt, 1989; Hughes, 2013), esforçando menos. Assim, os vendedores podem acreditar que um novo produto pode vender-se por si só e com pouco esforço e, como resultado, eles podem desviar os esforços para outros produtos na carteira.

Dessa forma, se o vendedor acredita que a tarefa de vender um novo produto é mais fácil, dada sua inovação, há uma tendência de ele investir uma menor quantidade de esforço na venda do produto (Van den Bulte \& Lilien, 2001). Em pesquisa recente, Ahearne, Rapp et al. (2010) suportaram essa hipótese quando identificaram que representantes comerciais apresentaram pouco esforço quando o índice de percepção sobre o novo produto era maior. Portanto, a primeira hipótese é:

$\mathbf{H}_{1}$ : A percepção do vendedor sobre o novo produto tem relação negativa com o esforço do vendedor.

Oliver e Anderson (1994) destacam que em um sistema de controle do comportamento existe uma tolerância da empresa com resultados negativos das vendas por um determinado período, pois o vendedor pode estar utilizando esse tempo para aprender sobre os procedimentos e produtos da empresa. Nesse sentido, a empresa continua com o pagamento de salário mesmo com baixo desempenho, pois o vendedor está obtendo as instruções de aprendizagem da empresa. Num sistema de controle de resultado, ocorre o oposto. $\mathrm{O}$ vendedor é motivado pelo autointeresse imediato, portanto, a empresa remunera o vendedor de acordo com comissões proporcionais ao volume de vendas. Nesse contexto, Oliver e Anderson (1994) sugerem que pessoas com maior aversão ao risco se adaptam melhor ao controle por comportamento, enquanto pessoas com menor aversão ao risco se adaptam melhor ao controle por resultado.

Os novos lançamentos de produtos são associados ao risco, pois tanto os clientes quanto os vendedores ainda não possuem informações acerca dos benefícios e das consequências do consumo do produto, havendo então o risco. Assim, os vendedores, principalmente impulsionados pela aversão ao risco (Eisenhardt, 1989), podem ser relutantes em investir recursos e esforços em novos produtos. Todavia, cabe ressaltar que vendedores normalmente são remunerados por resultados de vendas globais, principalmente em sistemas de controle por resultado. Então, poder-se-ia esperar uma interação do sistema de controle com a percepção do vendedor sobre o novo produto.

Em um sistema de controle baseado em comportamento, o vendedor é remunerado mesmo em condições de baixo desempenho, desde que siga as diretrizes da empresa. Assim, a empresa pode determinar, via controle, que os esforços do vendedor sejam alocados num produto focal, independente de sua percepção sobre o potencial do mesmo, pois o vendedor não precisará se preocupar com seus resultados de vendas globais. Então, poderia haver uma interação entre o sistema de controle da empresa e a percepção do vendedor sobre o novo produto no que tange a influência de seu esforço. Assim sendo, tem-se:

$\mathbf{H}_{2}$ : Sistema de controle modera a relação entre a percepção do vendedor sobre o novo produto e o esforço.

Em relação ao desempenho das vendas, Cravens, Ingram, LaForge e Young (1993) realizaram um estudo para determinar os critérios do desempenho de vendas, encontrando inúmeros construtos preditores que explicavam as diferenças no desempenho dos vendedores por território. Dentre esses 
construtos, destaca-se o esforço dos vendedores. Acredita-se que, quanto maior o esforço, maior o resultado empresarial. Pesquisas anteriores mostraram uma relação positiva entre esforço e desempenho (Brown, Evans, Mantrala, \& Challagalla, 2005; Brown \& Peterson, 1994). Em pesquisa recente para testar os efeitos indiretos das percepções de publicidade no esforço do vendedor e no desempenho da empresa, Hughes (2013) entrevistou 197 vendedores de 18 grandes distribuidoras de bebidas. O autor demonstrou uma correlação significativa e forte entre o esforço dos vendedores e o desempenho das vendas.

Para Bergen, Dutta e Walker (1992), os vendedores utilizam critérios para atribuir esforços para maximizar o desempenho global. Empregando maior esforço sobre o novo produto, o vendedor é mais susceptível de fornecer ao cliente informações atuais, relevantes e úteis, elevando o desempenho. Por consequência, o nível elevado de esforço também transmite ao cliente o valor agregado do produto e a segurança do vendedor no produto (Ahearne, Rapp et al., 2010). Dessa forma, acredita-se que a decisão de fazer mais esforço para vender um produto em particular, quando há outros produtos na carteira do vendedor que poderiam também receber atenção (Hughes, 2013), gere um impacto positivo no desempenho. Entende-se que essa relação é mais suscetível de acontecer no canal vendedor-cliente, porque não há direta relação com o fabricante (Hughes, 2013). Assim, sugere-se:

\section{H3: Esforço tem uma relação positiva com desempenho.}

Conforme destacam Oliver e Anderson (1994), o gerente de vendas sugere ideias aos vendedores sobre o que eles devem fazer para obter melhores resultados, mesmo que no longo prazo. Assim, um sistema de controle por comportamento pode recompensar um vendedor que intensifique o esforço em produtos lançados recentemente, como estratégia de introdução de novos produtos. Dessa forma, acredita-se que no sistema de controle baseado em comportamento, os gestores podem direcionar os vendedores para executar certos comportamentos como parte da estratégia da empresa, sem a necessidade de convencer cada vendedor de qual estratégia é a mais apropriada.

A vantagem de se adotar um sistema de controle baseado em resultados ocorre em virtude da natureza da atividade de vendas. Segundo Oliver e Anderson (1994), vender é uma atividade profissional independente e que ocorre no âmbito micro (vendedor-cliente), o que torna a supervisão difícil. Além do mais, Weitz (1981) destaca que é extremamente difícil traçar o perfil do vendedor de sucesso, o que torna a ocupação do vendedor extremamente complexa. Assim, em virtude de que muitos tipos de pessoas e de muitos métodos de operação parecem ter sucesso em um cenário e não em outro, o desenvolvimento de estratégias específicas para cada situação é difícil (Oliver \& Anderson, 1994), o que torna muito complexo determinar quais inputs dos vendedores tornam-se outputs. Diante dessa complexidade, as organizações preferem adotar sistemas de controle por resultado, nos quais os vendedores são livres para usarem seus próprios métodos, mas também são responsabilizados pelo que deles resulta.

Ahearne, Rapp et al. (2010) obtiveram evidências de que o esforço impacta positivamente a percepção do cliente sobre um novo produto e que o sistema de controle por comportamento reduz a percepção do cliente. Isso ocorre pois o vendedor tem que cumprir uma série de padrões préestabelecidos independentemente de qual forma ele considera mais adequada para aquela situação. Além disso, é obrigado a empurrar um produto da carteira em que ele não acredita que mereça ser direcionado o seu esforço. Assim, sob um sistema de controle baseado em comportamento, Ahearne, Rapp et al. (2010) encontraram que o vendedor é menos provável de ser capaz de adaptar seu esforço para atender exigências específicas dos clientes e, como resultado, há uma relação mais fraca entre esforço do vendedor e percepção do produto pelo cliente, consequentemente, afetando o desempenho do vendedor. Diante do apresentado, sugere-se que:

$\mathbf{H}_{4}$ : Sistema de controle modera a relação entre esforço com vendas e desempenho.

Moreau, Lehmann e Markman (2001) avaliaram a resposta do consumidor para novos produtos, apresentando a distinção entre inovação contínua e inovação descontínua. Para esses autores, a inovação é resultado de uma alteração ou eliminação de atributos de produtos ou recursos dentro de uma categoria 
existente. Dessa forma, os novos produtos, denominados pelos autores como inovação descontínua, são frequentemente derivados de uma ou mais categoria de produtos existentes. Para os autores sustentarem esse ponto de vista, utilizam a argumentação de Ward (2004, p. 184), que define esse fenômeno como "imaginação estruturada", e que sugere que as pessoas utilizem sua imaginação para desenvolver novas ideias. O resultado dessas ideias é um forte reflexo da estrutura do conhecimento de propriedades de categorias existentes. Nesse sentido, novos produtos com um alto nível de alteração ou eliminação de atributos em relação ao conhecimento precedente dos clientes são classificados como inovações descontínuas; mas, se o produto apresenta um nível de mutabilidade baixo para a alteração ou eliminação de atributos, são classificados como inovações contínuas. Neste estudo, o produto Victoza ${ }^{\circledR}$ e o Volkswagen UP®, ambos analisados nos Estudos 1 e 2, são inovações descontínuas. Diante do exposto, acredita-se que a inovação descontínua, por possuir uma quebra mais relevante de paradigma no comportamento de compra, faz com que haja menor esforço com vendas. Portanto, o produto poderia vender-se por si só, sem empregar grande carga de esforço. Dessa forma, tem-se:

H5: O nível de inovação influencia negativamente o esforço do vendedor na venda do novo produto.

A Figura 1 apresenta o modelo teórico do trabalho, o qual é examinado com dados de vendedores em dois estudos independentes. O sistema de controle atua como moderador das relações que explicam desempenho e esforço (ver setas pontilhadas). As demais relações que foram elaboradas são relações diretas (ver setas contínuas). As covariáveis corrigem os níveis de variância do desempenho.

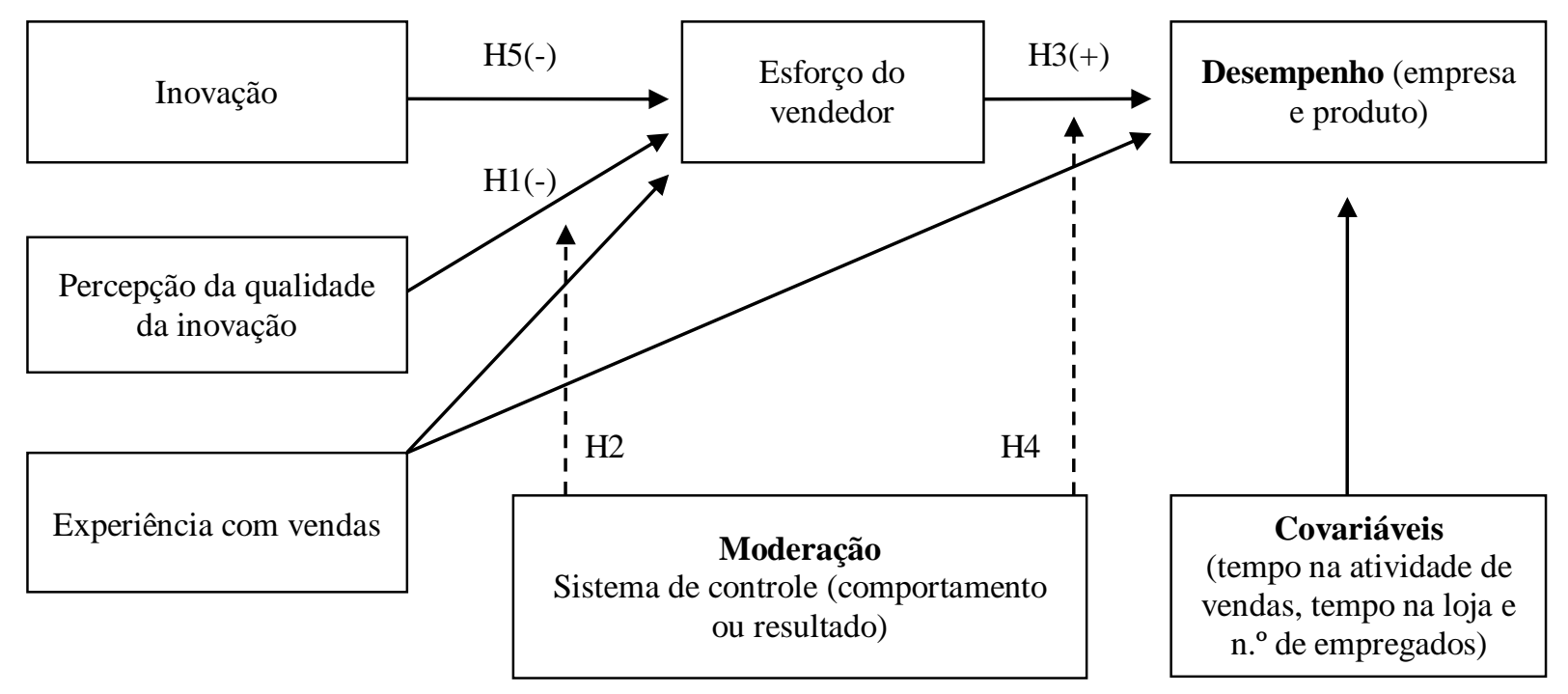

Figura 1. Modelo Conceitual Proposto dos Antecedentes do Desempenho com Vendas

\section{Estudo 1}

Escolha do produto. Como a pesquisa tem o intuito de mensurar a percepção da qualidade da inovação e o esforço para a venda do lançamento da inovação, dez farmacêuticos foram entrevistados apresentando pontos de vista sobre produtos inovadores. Após tal processo, o medicamento Victoza ${ }^{\circledR}$ foi escolhido por ser considerado um produto inovador, que teve lançamento há aproximadamente 12 meses antes da data da pesquisa (meados de março de 2013).

Produto Inovador. Victoza ${ }^{\circledR}$ é um medicamento injetável aprovado pela ANVISA indicado para combater a Diabetes Tipo II, a qual ocorre principalmente em pessoas com obesidade. O princípio ativo, a liraglutida, ajuda a regular a produção dos hormônios insulina e glucagon. Por outro lado, uma dose 
diária de Victoza ${ }^{\circledR}$ tende a emagrecer em média 3 quilos por mês mantendo suas atividades normalmente. Portanto, o medicamento também é utilizado para emagrecimento. O lançamento do medicamento nos EUA foi em 2010 e, no Brasil, em 2011. Na capa da revista Veja (Editora Abril, 2011) encontra-se a seguinte chamada: "Parece milagre! Novo remédio faz emagrecer 7 a 12 quilos em cinco meses. E sem grandes efeitos colaterais".

Procedimentos e Amostra. Após pré-teste do questionário e correções das questões, definiu-se a amostra de vendedores de balcão de farmácias. Os atendentes de balcão e farmacêuticos foram abordados in loco e, após receberem a explicação dos objetivos da pesquisa, foram convidados a participar dela. Foram distribuídos 200 questionários pessoalmente nas empresas abordadas. No entanto, apenas 127 optaram por preenchê-lo, totalizando uma taxa de resposta de 63\%. Um questionário precisou ser descartado e a amostra final foi de 126. A técnica de amostragem utilizada foi a não probabilística por julgamento (Teddlie \& Yu, 2007).

Mensuração. Inovação é a percepção de quão inovador é o produto. Os indicadores utilizados para mensurar inovação do produto foram retirados do texto de Ahearne, Rapp et al. (2010). Os mesmos são: o nível de inovação do produto era; o nível de novidade do produto era; e o impacto da inovação foi; todos variando de nada $=1$ até alto $=10$.

Percepção da qualidade da inovação do produto é o nível de eficiência, eficácia, segurança e capacidade efetiva e racional do produto. Com base em Ahearne, Rapp et al. (2010), os quatro indicadores utilizados para mensurar percepção da qualidade da inovação do produto pelo vendedor são: Naquela época, há $x$ meses atrás, você acreditava que o produto era eficaz; seguro; útil e aceitação do mercado, variando de pouco $=1$ até excelente $=10$.

Experiência é a percepção de senioridade dos vendedores quanto à atuação em vendas. Com base em Ahearne, Rapp et al. (2010), os cinco indicadores para mensurar experiência são: Naquela época, há $x$ meses atrás, você se autoavaliava como; Minha experiência na farmácia era; Meu conhecimento geral com vendas; Minha experiência com os medicamentos e marcas; e Minha experiência no mercado farmacêutico, variando de baixo $=1$ até excelente $=10$.

Em alinhamento com Oliver e Anderson (1994), controle do vendedor possui duas dimensões, sendo que a primeira, controle do comportamento, tem os seguintes indicadores: A empresa faz controle estrito de minhas atividades e comportamentos; A empresa monitora minhas ações diária e regularmente; e A empresa acompanha as ações dos vendedores dia a dia, variando de nunca faz até sempre faz. A dimensão controle do resultado tem os seguintes indicadores: A empresa paga comissões para os vendedores; A empresa deixa os vendedores livres para trabalhar; A empresa possui pouco monitoramento dos vendedores; e A empresa não faz checagem diária dos trabalhos dos vendedores, variando de discordo totalmente $=1$ até concordo totalmente $=10$. Antes das questões havia uma instrução para responder com base nos dias atuais. Os indicadores são adaptados de Miao, Lund e Evans (2009).

Os três indicadores para mensurar esforço de vendas no momento passado, época de lançamento do produto, são: Naquela época, a quantidade de argumentos para vender era; Naquela época meu esforço em vender o produto era; e Naquela época meu empenho em vender o produto era, variando de pouco $=1$ até muito $=10$. Os três indicadores para mensurar esforço de vendas no momento presente são Hoje, meu empenho em vendas deste produto é; Hoje, a quantidade de argumento de vendas para vender é; e Hoje, meu esforço em vendas deste produto é. Os indicadores são com base em Ahearne, Rapp et al. (2010).

Os cinco indicadores para mensurar desempenho da farmácia são: Em termos de vendas, a nossa farmácia está indo; Em termos de lucros, a nossa farmácia está indo; Em termos de crescimento, a nossa farmácia está indo; Em termos de participação de mercado, a farmácia está indo; e em termos de vendas desse medicamento inovador, ele está indo (atualmente), variando de muito mal=1 até muito bem=10. Demais perguntas de controle eram o tempo na área de vendas, o tempo que trabalha na empresa e a quantidade de funcionários na farmácia. Os indicadores são com base em Vieira, Galeano e Pires (2013). 


\section{Resultados - Estudo 1}

Um total de 127 vendedores de farmácias que atuam no balcão responderam as questões. Um valor em branco foi encontrado e eliminado. O tempo médio de atuação na área de vendas é de $M=8,91$ anos com um desvio padrão (DP) $=7,46$, variando de 1 ano até 43 anos. O tempo médio de trabalho na empresa é de 5,44 anos ( $\mathrm{DP}=4,55)$, variando de 0 até 18 anos.

Antes de examinar as hipóteses sugeridas neste trabalho, exames de dimensionalidade, análise fatorial exploratória e confiabilidade das escalas foram realizados. Conforme o esperado, a dimensionalidade e a confiabilidade dos instrumentos de pesquisa foram adequados para o propósito do trabalho. Para os dois estudos, os itens apresentaram cargas fatoriais significativas na dimensão esperada. No estudo 1, os índices de confiabilidade alfa de Cronbach foram todos superiores a 0,70 (Nunnally, 2010), enquanto, no segundo, o valor mínimo foi 0,63.

Na Tabela 2, os valores na diagonal superior representam o Estudo 2 e na diagonal inferior o Estudo 1. A matriz de correlação mostra que o desempenho global da farmácia é influenciado positivamente pela percepção do novo produto $(r=0,31 ; p<0,01)$. No Estudo 2, a variável desempenho corresponde ao resultado das vendas do produto.

Tabela 2

\section{Matriz de Correlação dos Construtos}

\begin{tabular}{llcccccccccc}
\hline Variável & $\mathbf{1}$ & $\mathbf{2}$ & $\mathbf{3}$ & $\mathbf{4}$ & $\mathbf{5}$ & $\mathbf{6}$ & $\mathbf{7}$ & $\mathbf{8}$ & $\mathbf{9}$ & $\mathbf{1 0}$ \\
\hline 1 & Inovação do Produto & & $0,39^{* *}$ & $0,23^{* *}$ & $0,19^{*}$ & $0,31^{* *}$ & $0,22^{*}$ &, $28^{* *}$ & $-0,07$ & $-0,08$ & 0,02 \\
2 & Qualidade Inovação & $0,26^{* *}$ & &, $44^{* *}$ & $0,22^{*}$ & $0,32^{* *}$ & $0,19^{*}$ & 0,11 & $-0,09$ & $-0,13$ & 0,06 \\
3 & Experiência & $-0,04$ & 0,07 & & $0,30^{* *}$ & $0,30^{* *}$ & $0,21^{*}$ & 0,17 & $0,21^{*}$ & $0,27^{* *}$ & 0,02 \\
4 & Esforço & $-0,21^{*}$ & $-0,10$ & 0,09 & & $0,22^{*}$ & $0,52^{* *}$ & $0,51^{* *}$ & $-0,13$ & 0,04 & $-0,32^{* *}$ \\
5 & C. Comport. & 0,00 & $0,18^{*}$ & $-0,04$ & $-0,04$ & & $0,28^{* *}$ & 0,12 & 0,00 & $-0,11$ & $0,46^{* *}$ \\
6 & C. Resultado & 0,04 & $0,23^{* *}$ & 0,08 & $-0,23^{*}$ & $0,28^{* *}$ & & $0,33^{* *}$ & $-0,05$ & 0,05 & $-0,71^{* *}$ \\
7 & Desempenho & $0,31^{* *}$ & 0,10 & 0,06 & $-0,14$ & $-0,11$ & 0,17 & & $-0,01$ & 0,03 & $-0,22^{*}$ \\
8 & Tempo Vend. & $-0,01$ & 0,11 & $0,46^{* *}$ & 0,11 & $-0,10$ & $0,17^{*}$ & $-0,05$ & & $0,62^{* *}$ & 0,04 \\
9 & Tempo Empr. & 0,07 & 0,11 & $0,55^{* *}$ & 0,02 & 0,04 & $0,28^{* *}$ & 0,04 & $0,51^{*}$ & & $-0,12$ \\
10 & S. Controle & 0,00 & $0,23^{*}$ & 0,05 & $-0,11$ & $0,67^{* *}$ & $0,75^{* *}$ & 0,02 & 0,13 & $0,19^{*}$ & \\
\hline
\end{tabular}

Nota. Sistema de controle global significa se positivo é comportamento; Pearson; N = 126 vendedores. Valores na diagonal superior representam o estudo 2 (produto VW UP®) ).

Escala varia de 1 até $10, * p<0,05 ; * * p<0,01$.

Equações. Vários modelos foram estimados para exame das hipóteses. Inicialmente, no modelo baseline, apenas as covariáveis foram associadas, no sentido de controlar a variância explicada. Esse modelo não é listado na Tabela 3 por motivos de espaço. No primeiro modelo, os efeitos diretos (main effects) foram verificados, sendo as suposições: $\mathrm{H}_{1}, \mathrm{H}_{3}$ e $\mathrm{H}_{5}$. Nos segundo e terceiro modelos, dada a moderação do sistema de controle (interactive effect), duas equações de moderação foram feitas para examinar a variância do esforço e do desempenho, sendo $\mathrm{H}_{2}$ e $\mathrm{H}_{4}$. 
Tabela 3

\section{Coeficientes das Estimativas das Regressões}

\begin{tabular}{|c|c|c|c|c|c|c|c|c|c|c|c|c|}
\hline \multirow{3}{*}{ Covariáveis } & \multicolumn{6}{|c|}{ Estudo 1 - Inovação Victoza ${ }^{\circledR}$} & \multicolumn{6}{|c|}{ Estudo 2 - Inovação UP® } \\
\hline & \multicolumn{3}{|c|}{ Desempenho (Geral) } & \multicolumn{3}{|c|}{ Esforço de Vendas } & \multicolumn{3}{|c|}{ Desempenho (Produto) } & \multicolumn{3}{|c|}{ Esforço de Vendas } \\
\hline & & & & & & & & & & & & \\
\hline Tempo de vendas & $-0,13$ & $-0,12$ & $-0,15$ & 0,14 & 0,14 & 0,15 & 0,09 & 0,11 & 0,06 & $-0,37 * *$ & $-0,30^{*}$ & $-0,36^{* *}$ \\
\hline Tempo de empresa & 0,06 & 0,07 & 0,05 & $-0,03$ & $-0,03$ & $-0,02$ & $-0,07$ & $-0,06$ & $-0,06$ & $-0,04$ & $-0,01$ & $-0,02$ \\
\hline Número de empregados & $0,37 * * *$ & $0,36 * * *$ & $0,33 * * *$ & $-0,11$ & $-0,11$ & $-0,08$ & & & & & & \\
\hline Tempo de vendas de veíc. & & & & & & & 0,02 & $-0,03$ & 0,00 & $0,29 \dagger$ & 0,21 & $0,24 \dagger$ \\
\hline Perc. Comissão (\%) & & & & & & & $-0,01$ & 0,01 & $-0,01$ & 0,11 & 0,11 & 0,06 \\
\hline \multicolumn{13}{|l|}{ Efeitos Diretos } \\
\hline $\begin{array}{l}\mathrm{H}_{1} \text { : Percep. Qualidade da } \\
\text { Inovação }\end{array}$ & & & & $-0,19^{*}$ & $-0,18 \dagger$ & $-0,18^{*}$ & & & & 0,13 & $0,21 *$ & $0,24 *$ \\
\hline $\begin{array}{l}\mathrm{H}_{3} \text { : Esforço na venda do } \\
\text { produto }\end{array}$ & $-0,05$ & $-0,02$ & $-0,02$ & & & & $0,50 * * *$ & $0,39 * *$ & $0,39 * * *$ & & & \\
\hline $\mathrm{H}_{5}$ : Inovação & & & & $-0,06$ & $-0,06$ & $-0,08$ & & & & 0,04 & $-0,01$ & $-0,05$ \\
\hline Experiência em vendas & $-0,00$ & 0,00 & 0,10 & 0,08 & 0,08 & $-0,01$ & 0,02 & 0,01 & 0,09 & $0,26 * *$ & $0,29 * *$ & $0,29 * *$ \\
\hline Sistema de controle & $-0,17 \dagger$ & $-0,15$ & 0,50 & $0,16 \dagger$ & 0,26 & $-0,39$ & $-0,07$ & $-0,57$ & $-0,11$ & $-0,35 * *$ & $-0,30 * * *$ & $-0,34 * * *$ \\
\hline \multicolumn{13}{|l|}{ ModeraçãoDupla } \\
\hline $\begin{array}{l}\mathrm{H}_{2} \text { : Percep. Qualid. Inov. × } \\
\text { Sist. Controle }\end{array}$ & & & & & $-0,10$ & & & & & & $0,31 * * *$ & \\
\hline $\mathrm{H}_{4}$ : Esforço $\times$ Sist. Controle & & $-0,06$ & & & & & & 0,48 & & & & \\
\hline \multicolumn{13}{|l|}{ Outras Suposições } \\
\hline $\begin{array}{l}\text { Experiência } \times \text { Sistema } \\
\text { Controle }\end{array}$ & & & $-0,71 *$ & & & $0,58 \dagger$ & & & $0,25^{* *}$ & & & $0,38 * * *$ \\
\hline $\mathbf{R}^{2 \text { ajustado }}$ & $17 \%$ & $17 \%$ & $20 \%$ & $6 \%$ & $5 \%$ & $7 \%$ & $24 \%$ & $24 \%$ & $28 \%$ & $24 \%$ & $32 \%$ & $38 \%$ \\
\hline
\end{tabular}


As equações interativas com a multiplicação das variáveis contínuas foram utilizadas conforme sugerido por Aiken e West (1991). As variáveis foram padronizadas e optou-se pela elaboração dos efeitos multiplicativos (Hayes, 2013) resolvendo os problemas de multicolinearidade (Echambadi \& Hess, 2007). Para fins de plotagem dos gráficos, os dados não padronizados são utilizados. No quarto modelo, os efeitos da experiência interagindo com o sistema de controle são analisados. A Tabela 3 apresenta os achados dos modelos e respectivos coeficientes.

No Estudo 1, utilizando apenas as três covariáveis como independentes, a variância explicada de desempenho foi de $16 \%$. A primeira hipótese descreve que a percepção do vendedor sobre o novo produto influencia negativamente o esforço do vendedor. Os achados evidenciaram uma relação significativa e mostraram que, quanto mais o vendedor observou e notou que o produto é novo, houve menos esforço para vendê-lo $\left(\beta=-0,19 ; p<0,05 ; \mathrm{H}_{1}\right)$. Esse achado pode ser explicado pelo fato de que a inovação facilita o nível de empenho. Essas evidências tendem a dar suporte de que o novo produto pode levar o vendedor a acreditar na superioridade e a se esforçar menos, conforme Eisenhardt (1989) e Van den Bulte e Lilien (2001).

A próxima hipótese expõe que o esforço do vendedor influencia positivamente o desempenho da farmácia $\left(\mathrm{H}_{3}\right)$. Os achados evidenciaram que não houve uma relação $(\beta=-0,05 ; p=\mathrm{NS})$. No Estudo 1 , o esforço é uma percepção do passado menos o presente, criando uma variável delta. Não foi possível fazer uma coleta longitudinal, a qual daria mais confiabilidade a uma métrica desse tipo. Portanto, esse ponto poderia ser uma explicação para o resultado inesperado.

A hipótese $\mathrm{H}_{5}$ descreve que a inovação do produto influencia negativamente o esforço do vendedor. Os achados evidenciaram que houve uma relação negativa, conforme o esperado, embora não significativa $(\beta=-0,06 ; p=\mathrm{NS})$. A inovação do produto per si não necessariamente reduz o esforço em vender algo diferente, embora a percepção da qualidade da inovação do medicamento sim. Nota-se que, na matriz de correlação, essa relação foi significativa e negativa, conforme o esperado $(r=-0,21 ; p<$ $0,01)$. Compreende-se que, como a regressão utiliza mais variáveis independentes e há efeitos dentre elas, o resultado final foi não significativo. Diante desse ponto, a $\mathrm{H}_{5}$ foi rejeitada.

As próximas hipóteses assumem uma relação de moderação dos diferentes níveis de sistema de controle do vendedor na relação entre o esforço com vendas e o desempenho $\left(\mathrm{H}_{4}\right)$ e na relação entre percepção da qualidade do produto inovador e esforço $\left(\mathrm{H}_{2}\right)$. Embora o sistema de controle possua duas dimensões, para fins de operacionalização optou-se por diminuir uma dimensão da outra, sendo que maiores ( $v s$. menores) escores significam controle do comportamento ( $v s$. resultado). Esse é o mesmo modo de operacionalização sugerido por Anderson e Oliver (1987) e empregado por Ahearne, Rapp et al. (2010).

No caso de encontrar coeficientes de regressão significativos, as moderações foram interpretadas a partir de análises gráficas de Aiken e West (1991), representadas nas Figuras 2 e 3, sendo dos Estudos 1 e 2 respectivamente. Para tanto, os valores das variáveis dependentes (esforço em vendas e desempenho) foram estimados para as combinações possíveis entre altos e baixos valores das variáveis independente e moderadora multiplicados por seus respectivos coeficientes de regressão. Altos valores foram considerados pela média +1 desvio padrão e baixos valores pela média -1 desvio padrão (West, Aiken, \& Krull, 1996), tendo por base os dados dos gráficos tipo spotlights que foram criados (Spiller, Fitzsimons, Lynch, \& McClelland, 2013). 

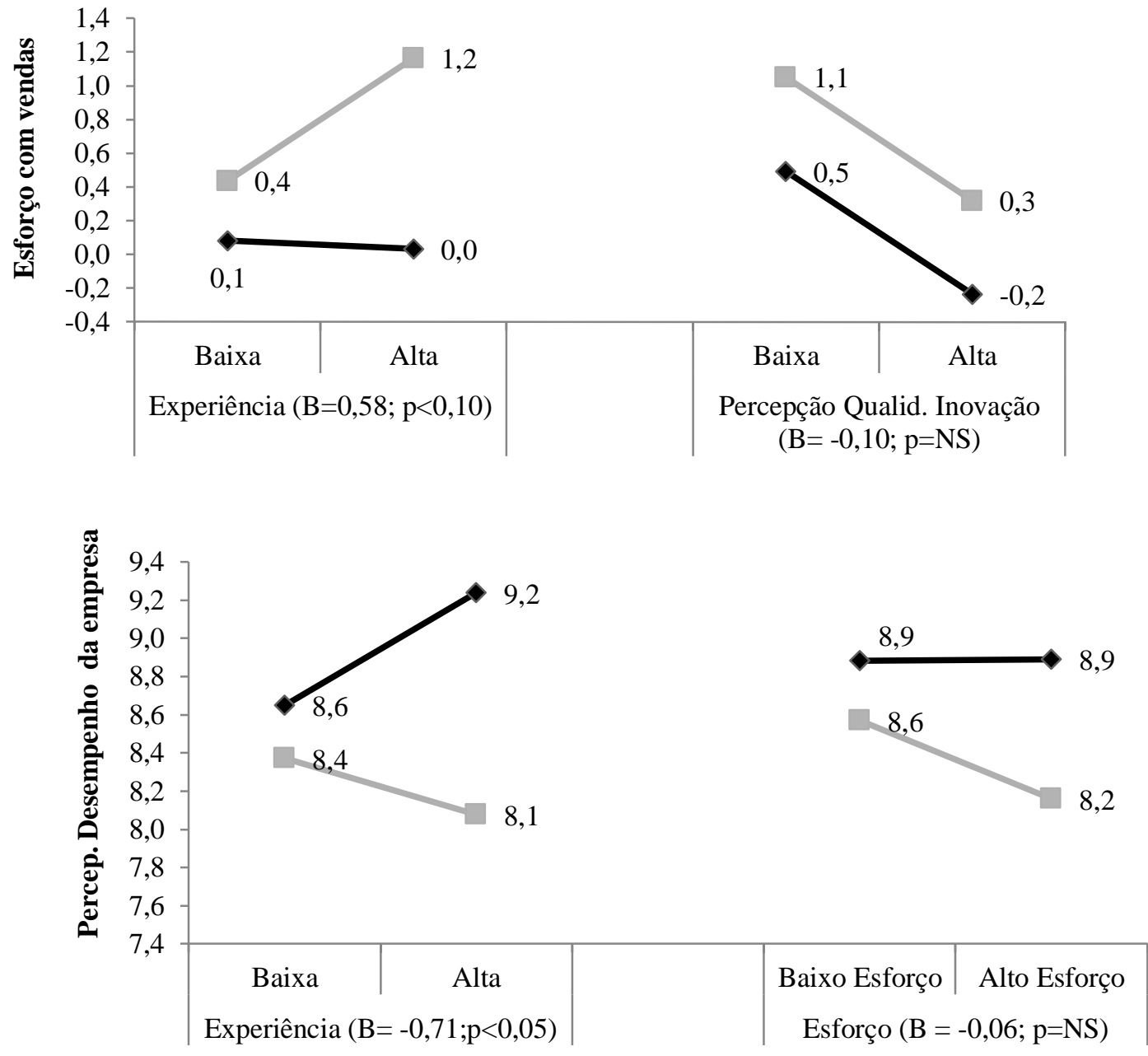

$\longrightarrow$ - Sistema Controle Resultado $\quad-\quad-$ Sistema Controle Comportamento

Figura 2. Efeitos Moderadores no Estudo 1 

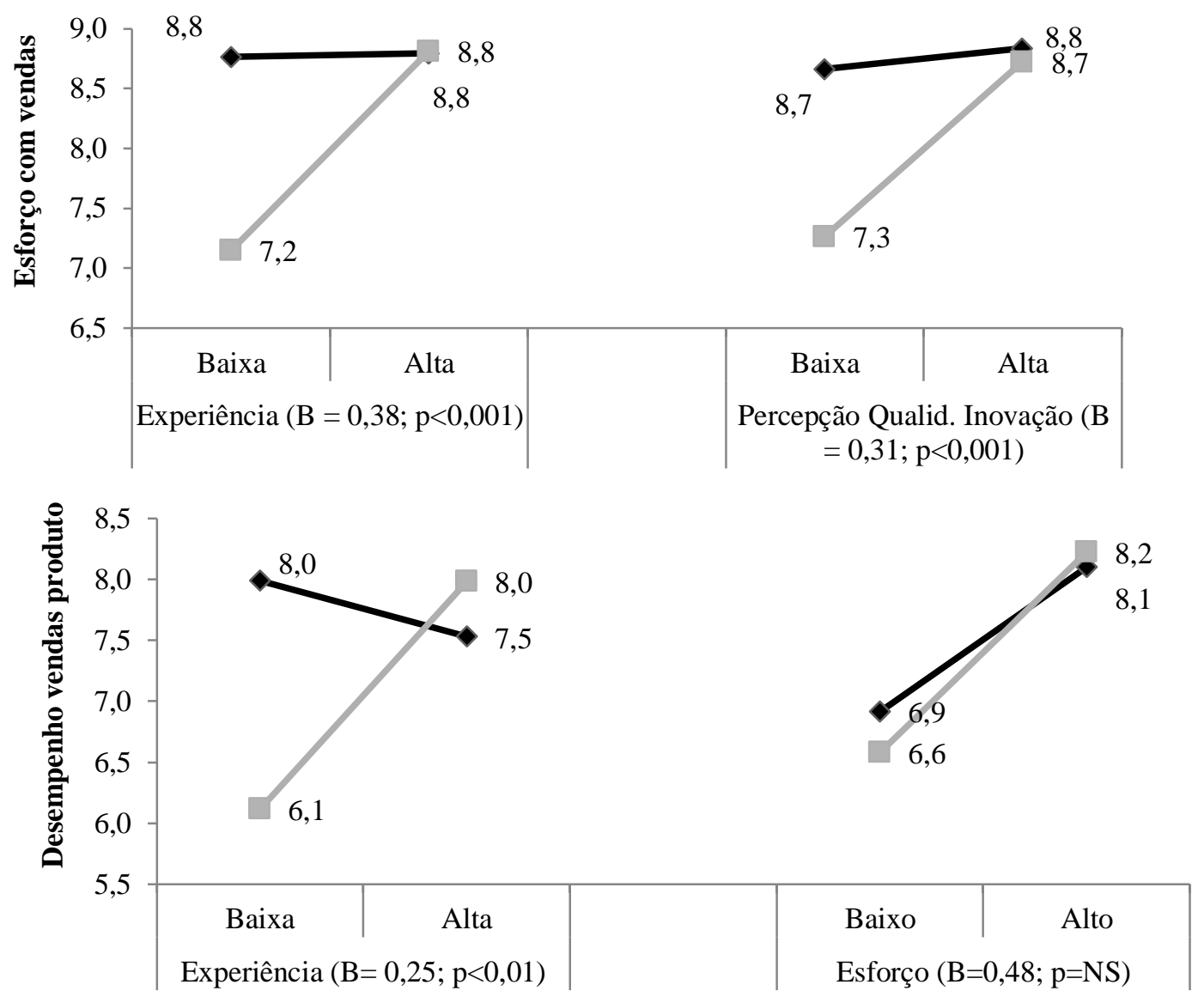

— Sistema Controle Resultado $\quad-$ Sistema Controle Comportamento

Figura 3. Efeitos Moderadores no Estudo 2

Inicialmente, $\mathrm{H}_{2}$ sugere que o sistema de controle modera a relação entre percepção da qualidade da inovação e esforço. No Estudo 1, a relação foi negativa, porém, não significativa $(\beta=-0,10 ; p=\mathrm{NS})$. Portanto, não há interferência da variável moderadora. Ao examinar a Figura 2, percebe-se que, enquanto no sistema de controle por resultado, a relação entre percepção e esforço é negativa, no sistema de controle por comportamento, a relação continua negativa. Portanto, não há variabilidade. Sendo assim, esses achados não são coerentes com a hipótese de moderação, rejeitando-se $\mathrm{a}_{2}$.

A hipótese $\mathrm{H}_{4}$ assume uma relação de moderação do sistema de controle na relação entre esforço e desempenho. Quando o sistema de controle foi inserido na relação, os achados mostraram que não houve relação $(\beta=-0,06 ; p=\mathrm{NS})$, não suportando a hipótese de moderação. De acordo com a Figura 2 , produto Victoza, a reta evidencia que, no sistema de controle por resultado, não há relação entre esforço e desempenho. Todavia, quando o sistema de controle é por comportamento, o resultado é negativo, prejudicando o desempenho. A hipótese sugeria um aumento no desempenho, evidenciando uma amplificação na relação.

Por fim, optou-se por examinar a relação entre experiência e esforço, e entre experiência e desempenho, ambas moderadas pelo sistema de controle. No que tange a primeira associação, de acordo com a Figura 2, a qual representa o Estudo 1, a moderação evidencia que quando o controle é por comportamento, a relação entre experiência e esforço é positiva $(\beta=0,58 ; p<0,10)$. Todavia, quando o controle é por resultado, a relação entre experiência e esforço é nula, variando quase nada. Embora não hipotetizado, esse achado é coerente com $\mathrm{H}_{2}$ e $\mathrm{H}_{4}$. 
Por fim, examinou-se a relação entre experiência e desempenho, moderada pelo sistema de controle. $\mathrm{O}$ sistema de controle modera a relação entre experiência e desempenho $(\beta=-0,71 ; p<0,05)$, mas a direção da média não foi como o esperado. De acordo com a Figura 2, a moderação evidencia que, quando o controle é por comportamento, a relação entre experiência e desempenho é negativa (onde se esperada positiva). Quando o controle é por resultado, contrariamente, a associação se torna positiva.

\section{Estudo 2}

Escolha do produto. Inicialmente, seis entrevistas foram feitas junto aos gerentes de equipe de vendas da Volkswagen indagando qual era o produto com maior grau de inovação da marca. As respostas apontaram o veículo Volkswagen UP®. Os mesmos descreveram de forma espontânea uma lista com quais produtos apresentam maiores inovações. Todos destacaram o Volkswagen UP® em primeiro lugar.

Produto Inovador. O Volkswagen UP® é um modelo de veículo que se enquadra no nicho de mercado para automóveis compactos e com baixo consumo de combustível, atendendo as demandas de sustentabilidade e saturação de espaço das grandes cidades atuais.

Procedimentos e Amostra. O Estudo 2 foi realizado com vendedores das concessionárias da Volkswagen. A coleta dos dados foi realizada in loco por meio de questionários entregues por um dos pesquisadores aos vendedores em 6 concessionárias e foi complementada por meio de pesquisa online em outras 11 concessionárias, utilizando o software Qualtrics. Nas duas formas de coleta, o primeiro contato foi realizado com o gerente da empresa, no qual foi explicado o teor da pesquisa e solicitada uma permissão para realizá-la. Por meio de contato com gerentes das 17 concessionárias de veículos Volkswagen do Estado do Paraná, os questionários foram encaminhados para 221 vendedores e foi obtido um total de 132 questionários respondidos, ou seja, uma taxa de resposta de aproximadamente $60 \%$. Desse total, seis foram descartados por possuírem todas as respostas iguais e um por ter sido respondido em menos de um minuto no Qualtrics, resultado em uma amostra final de 125 vendedores. A técnica de amostragem utilizada foi a não probabilística por julgamento (Teddlie \& Yu, 2007).

Mensuração. As escalas do Estudo 2 são iguais às do Estudo 1, salvo algumas exceções. Para mensurar o grau de inovação do produto, optou-se por utilizar a escala de Fu, Jones e Bolander (2008). Os indicadores são: $\mathrm{O}$ produto _ representa uma nova categoria de produtos para a nossa empresa; $\mathrm{O}$ produto _ é totalmente novo para o mercado; O produto __é um dos primeiros produtos do seu tipo no mercado; O produto _ é altamente inovador; e $\mathrm{O}$ produto _ tem um impacto alto no mercado. A escala variava de $1=$ discordo totalmente até $10=$ concordo totalmente.

A escala para mensurar o esforço foi adaptada do estudo de Miao e Evans (2014) e os itens utilizados foram: Em comparação com os outros vendedores da minha empresa, eu trabalho muitas horas para realizar uma venda do Volkswagen UP; Eu não desisto facilmente quando enfrento um cliente difícil; Eu trabalho incansavelmente para vender um Volkswagen UP a um cliente até fechar o pedido de venda, variando de discordo totalmente $=1$ até concordo totalmente $=10$.

Por fim, para mensurar o desempenho de vendas daquele produto específico, foi adaptada a escala de Baldauf, Cravens e Wagner (2000). Esse é um diferencial do trabalho, pois, no Estudo 1, o desempenho de vendas foi o percebido pela organização. Os itens foram: A quantidade de Volkswagen UP® que eu vendo é; A margem de lucro das minhas vendas de Volkswagen UP® é; Em comparação com os outros vendedores da minha empresa, o meu resultado de vendas do Volkswagen UP® é, variando de péssima $=1$ até ótima $=10$. 


\section{Resultados - Estudo 2}

No Estudo 2, participaram da pesquisa 125 vendedores de veículos pertencentes às concessionárias Volkswagen. O tempo médio de atuação na área de vendas é superior ao estudo anterior, $M=11,47$ anos, com um desvio padrão $=6,60$, variando de 0 até 34 anos. O tempo médio de trabalho na empresa é de 7,56 anos ( $\mathrm{DP}=5,48)$, variando de 0 a 30 anos (ver Anexo).

O Estudo 2 evidenciou que o tempo de vendas na área do produto inovador $(\beta=0,09 ; p=\mathrm{NS}), \mathrm{o}$ tempo na empresa $(\beta=-0,07 ; p=\mathrm{NS})$, o tempo na venda de veículos $(\beta=0,02 ; p=\mathrm{NS})$ e o percentual de comissão na remuneração final $(\beta=-0,01 ; p=\mathrm{NS})$ não influenciaram no desempenho de vendas do produto inovador.

Os resultados das análises mostraram que o esforço na venda do produto inovador foi relacionado positiva e diretamente com o desempenho nas vendas do próprio produto $(\beta=0,50 ; p<0,001)$. Esse achado suporta a hipótese $\mathrm{H}_{3}$. Os achados das análises mostraram que a percepção da qualidade da inovação não foi relacionada com o esforço de vendas $(\beta=0,13 ; p=\mathrm{NS})$. Esse achado rejeita a hipótese $\mathrm{H}_{1}$. $\mathrm{O}$ mercado automobilístico é marcado pelo alto grau de tecnologia dos produtos e por grandes competidores que inserem produtos inovadores simultaneamente no mercado. Deste modo, mesmo o produto sendo reconhecido como inovador, o vendedor não pode reduzir o nível de esforço, sob pena de não realizar a venda. No ramo de medicamentos, há uma defesa da patente por algum período. Dados tais achados, a $\mathrm{H}_{1}$ foi suportada apenas no Estudo 1, quando há uma inovação e uma patente por trás do medicamento.

Por fim, as análises salientaram que a inovação não foi associada com o esforço de vendas $(\beta=$ $0,04 ; p=\mathrm{NS})$. Esse resultado rejeita a hipótese $\mathrm{H}_{5}$, embora na matriz de correlação o resultado seja o esperado $(\beta=0,19 ; p<0,05)$. Por fim, notou-se que $17 \%$ da variação do desempenho da farmácia e $24 \%$ do desempenho das vendas do automóvel descritos no modelo conceitual são explicados pelas variáveis independentes em conjunto com as variáveis de controle.

No Estudo 2, a interação entre percepção da qualidade da inovação e sistema de controle apresentou uma relação positiva e significativa com o esforço do vendedor $(\beta=0,31 ; p<0,001)$. Esse achado suporta a $\mathrm{H}_{2}$. $\mathrm{O}$ exame da direção da média evidenciado na Figura 3 mostra que, quando há o sistema de controle de comportamento, a relação entre percepção da qualidade da inovação e o esforço é amplificada. Quando há o sistema de controle de resultado, a relação entre a percepção da qualidade da inovação e o esforço é nula. Portanto, para a venda de veículos, o sistema de comportamento foi mais benéfico.

A hipótese $\mathrm{H}_{4}$ assume uma relação de moderação do sistema de controle na relação entre esforço e desempenho. Quando o sistema de controle foi inserido na relação, os achados mostraram que não houve relação $(\beta=0,48 p=\mathrm{NS})$, não suportando a hipótese de moderação.

Por fim, verificou-se a interação do sistema de controle sobre a relação entre experiência e desempenho ou esforço. Notou-se que o sistema de controle interfere no modo como a experiência se associa com esforço com vendas $(\beta=0,38 ; p<0,001)$. Quando o controle é por resultado a relação é nula. Já no controle por comportamento, a relação entre esforço e experiência do vendedor é crescente e positiva. Deste modo, é possível destacar que, ao adquirir experiência, o vendedor pode se dedicar menos às atividades e às estratégias importantes na visão da empresa, como a venda de um produto inovador, sendo o controle por comportamento uma medida eficiente para reverter esse cenário.

Notou-se que o sistema de controle interfere no modo como a experiência se associa com desempenho de vendas do produto $(\beta=0,25 ; p<0,001)$. Quando o controle é por resultado, a relação é inversa prejudicando o desempenho. Já no controle por comportamento, a relação entre esforço e experiência do vendedor é crescente e positiva, conforme o esperado. 


\section{Conclusões}

A primeira conclusão é que a percepção do vendedor realmente interfere no lançamento de novos produtos junto aos consumidores, pois, quanto mais o vendedor acredita que o novo produto é superior aos outros produtos concorrentes já existentes, menos propenso ele está em se esforçar para vender esse novo produto. Se o vendedor acredita que o novo produto vai vender-se por si só, ele estará propenso a contar com o auxílio dos suportes externos, como o marketing e a propaganda boca a boca, desviando esforços para outros produtos do portfólio. Isso ocorreu no produto Victoza ${ }^{\circledR}$, que poderia estar protegido pela lei de patente da inovação em medicamentos.

Todavia, o contrário ocorreu no Estudo 2. Quanto mais o vendedor acredita que o novo produto é superior aos outros produtos concorrentes já existentes, mais esforço ele está propenso a empregar para vender este novo produto. Isso ocorre pelo fato que Ford, Fiat, Chevrolet e outras também lançam produtos compactos no mesmo tempo que UP ${ }^{\circledR}$, gerando concorrência da inovação e maior esforço com vendas. Ou seja, mesmo reconhecendo a qualidade da inovação do produto, o vendedor empreende grande esforço na sua venda, até mesmo como uma forma de explorar ainda mais o potencial de vendas do produto.

Boehe, Milan e De Toni (2009) evidenciaram que, em mercados de alta intensidade competitiva, a introdução de novos produtos afeta a agressividade na resposta dos concorrentes, impactando, por conseguinte, o desempenho do novo produto. Portanto, nota-se que, em mercados acirrados, o esforço do vendedor é uma força indispensável para as empresas inovadoras, que não podem restringir suas ações mercadológicas apenas à publicidade. Esse fenômeno não foi presente na indústria farmacêutica, já que o produto é protegido da concorrência por patentes, gerando um mercado exclusivo e uma sensação de conforto ao vendedor.

Segundo, comprovou-se que o sistema de controle por comportamento tem um efeito melhor do que o sistema de controle por resultado na relação entre percepção da qualidade da inovação e esforço. De fato, nem todos os vendedores respondem da mesma forma a um sistema de controle (Ahearne $e t$ al., 2010). Isso foi demonstrado por Cron e Slocum (1986), os quais identificaram que, no início de suas carreiras, os vendedores apresentam um conhecimento ainda insuficiente sobre as competências e as habilidades necessárias para um desempenho eficaz. No entanto, durante o tempo, esses vendedores ganham experiência, fazendo com que seu conhecimento sobre o desempenho dos diversos produtos aumente (Rapp, Ahearne, Mathieu, \& Schillewart, 2006). No caso aqui encontrado, o sistema de controle por comportamento tem um efeito amplificador do impacto das variáveis antecedentes, e o sistema de controle por resultado tem um efeito redutor, prejudicando a relação.

Embora o efeito moderador do sistema de controle na relação entre percepção da qualidade da inovação e esforço não apresentou significância no Estudo 1, a direção das evidências permite concluir que um sistema de controle baseado em resultado, em que o vendedor é livre para escolher entre produtos existentes no seu portfólio, faz com vendedores fiquem predispostos a não se esforçarem mais para os novos produtos, independente do nível de percepção da qualidade da inovação. No Estudo 2, os resultados indicam que, quando o controle é por resultado, não há moderação na relação entre percepção da qualidade e esforço, apesar do nível de esforço nesse cenário ser alto. Não obstante, quando há um controle de comportamento, a relação entre percepção e esforço é crescente. Quanto maior o nível de controle, maior o esforço. Sendo assim, mesmo o controle de resultado apresentando também altos níveis de esforço em alguns cenários, um alto nível de controle por comportamento pode ser mais condizente com a estratégia adotada pela empresa de incentivo a produto inovador.

Terceiro, nota-se que o sistema de controle não apresenta efeito moderador na relação entre esforço e desempenho. A direção dos achados, entretanto, evidencia que, para o produto inovador, introduzido em mercado de baixa intensidade competitiva, o sistema de controle por comportamento faz com que o impacto do esforço no desempenho seja menor. Esse achado é consistente com os pressupostos de Anderson e Oliver (1987), no qual o desempenho em vendas não é uma preocupação para o vendedor cujo seu comportamento é estritamente controlado, pois, nesse caso, a organização 
assume o risco das vendas, incentivando o vendedor a melhorar sua atividade e processo de vendas. Ressalta-se que esse resultado não se aplica para produtos inovadores introduzidos em mercados com alto nível de intensidade competitiva.

Quarto, em relação à experiência em vendas, verificou-se que o elevado tempo de experiência do vendedor faz com que a relação negativa entre esforço e desempenho seja amenizada quando o sistema de controle é por resultado, ao passo que piora a relação negativa entre percepção da inovação e esforço quando o sistema de controle é por comportamento. Diante desses achados, cabe concluir que o vendedor experiente diante de um sistema por resultado apresenta uma independência maior diante da empresa, levando a acreditar que seu esforço impacta no desempenho. Entretanto, o vendedor experiente, quando se depara com um sistema por comportamento e tem maior conhecimento dos produtos que estão em seu portfólio, pode não aceitar de prontidão as normativas da empresa.

Diante dessas conclusões, destacam-se algumas implicações gerenciais. Em primeiro lugar, como as organizações buscam estratégias de inovação que visam à criação de produtos com características diferentes e com nível de qualidade mais elevado do que os produtos dos concorrentes (Boehe, Milan \& De Toni, 2009), na introdução de novos produtos em mercados com alto nível de concorrência, recomenda-se a adoção de sistemas baseados em controle por comportamento para direcionar o esforço de vendedores, pois pressupõe-se que os mesmos podem perceber o produto inovador com qualidade superior, portanto, os mecanismos de controle de comportamento incentivariam seus esforços para a venda do novo produto.

Uma segunda implicação está relacionada ao papel do vendedor para o desempenho de novos produtos. Gonçalves, Gonçalves e Pardini (2008) destacam a importância dos processos de gestão de conhecimento em marketing em relação ao desempenho de novos produtos, portanto, recomendam que empresas inovadoras desenvolvam capacidade em utilizar informações advindas de clientes, concorrentes e tecnologia para fomentar seu processo de gestão de inovação. Nesse cenário, a presente pesquisa destaca também a capacidade das empresas para gerir sua força de vendas como um fator preponderante para o sucesso dos novos produtos.

Por fim, os resultados demonstram a relação entre a experiência dos vendedores e o tipo de sistema de controle a ser adotado. Para vendedores com elevado nível de experiência, recomenda-se a adoção de sistemas de controle por resultados, pois o conhecimento do vendedor inerente às estratégias de vendas pode ser mais eficiente para determinado mercado e/ou produto, gerando melhores resultados para a organização. No entanto, esse aspecto deve ser visto com cautela para novos produtos, pois sistemas de controle por resultado não são adequados para produtos inovadores e desempenho, assim, recomenda-se que as organizações incluam a sugestão de vendedores experts, com o intuito de envolvêlos na introdução de novos produtos, inclusive, contando com sua interação e influência junto aos vendedores novatos. Essa implicação está em consonância com a perspectiva de redes sociais, presente no artigo de Claro e Laban (2011), na qual a construção de laços fortes entre os vendedores podem impactar de forma positiva no desempenho, sugerindo que as empresas estimulem contatos entre os seus vendedores e permitindo uma melhor difusão de informações técnicas e comerciais.

\section{Limitações da pesquisa}

Uma limitação do trabalho é explorar o desempenho por meio subjetivo e não pelo prisma objetivo da organização (ex. faturamento, vendas em valores absolutos, percentuais de comissão, etc.). Trabalhos têm coletados dados objetivos de desempenho via métricas de faturamento, de ticket médio ou mesmo de comissões, estimando regressões com dados agregados em modelos multiníveis (Ahearne, Rapp et al., 2010; Lindell \& Brandt, 1999). Neste trabalho, o desempenho foi mensurado pela percepção de quão bem as vendas estão indo, uma vez que as empresas não forneceram os dados da receita.

Segundo, pesquisas mostram que o controle por comportamento é mais associado à motivação intrínseca e que o controle por resultado é mais associado à motivação extrínseca (Cravens, Ingram, LaForge, \& Young, 1993). Com base nisso, dado que o artigo não utilizou a motivação como um 
condicionante, analisar a interatividade dessas duas variáveis em investigações futuras para explicar o desempenho pode ser um ponto relevante.

Terceiro, pesquisas que analisem os efeitos da motivação dos vendedores usando sistemas de controles híbridos com duas dimensões (vs. continuum) podem auxiliar no avanço da literatura de marketing e vendas, especialmente em novos ambientes de vendas, conforme abarcado por Brown Evans, Mantrala e Challagalla (2005) e Brown e Peterson (1994). Cravens, Lassk, Low, Marshall e Moncrief (2004) também discutem os sistemas híbridos como área de pesquisa.

Quarto, evidenciou-se que a concorrência ambiental é um fator relevante para a introdução de novos produtos, no entanto, essa variável não foi inserida no modelo teórico. Nesse aspecto, Homburg, Muller e Klarmann (2011) destacam que fatores macroambientais, como a intensidade competitiva, apresentam potencial para impactar no nível da orientação para o cliente de um vendedor e o seu desempenho. Especificamente para novos produtos, Boehe et al. (2009) demonstraram o efeito negativo que a intensidade competitiva tem sobre o desempenho. Portanto, pesquisas futuras que envolvam o desempenho de novos produtos e sistemas de controle da força de vendas devem levar em consideração a intensidade competitiva em seus modelos teóricos.

Por fim, destaca-se uma limitação relacionada ao prisma de análise dos sistemas de controle. Recentemente Leão e Mello (2010) propuseram um novo prisma de análise dos mecanismos de controle de marketing a partir da Teoria Institucional. Os autores argumentam que uma determinada organização, cujos significados possam ser enraizados na cultura de seu microambiente, torna-se, para esta, uma instituição. Assim, essa organização pode desenvolver um controle institucional de marketing, pois os seus significados seriam compartilhados pelos vendedores. Desse modo, futuras pesquisas podem encaminhar esse prisma de análise, com o intuito de verificar os significados que os vendedores atribuem ao controle institucional e se esse controle é partilhado por todos.

\section{Referências}

Ahearne, M., Mackenzie, S. E., Podsakoff, P. M., Mathieu, J., \& Lam, S. K. (2010). The role of consensus in sales team performance. Journal of Marketing Research, 47(3), 458-469. doi: $10.1509 / j m k r .47 .3 .458$

Ahearne, M., Mathieu, J., \& Rapp, A. (2005). To empower or not to empower your sales force? An empirical examination of the influence of leader empowerment behavior on customer satisfaction and performance. Journal of Applied Psychology, 90(5), 945-955. doi: 10.1037/00219010.90.5.945

Ahearne, M., Rapp, A., Hughes, D. E., \& Jindal, R. (2010). Managing sales force product perceptions and control systems in the success of new product introductions. Journal of Marketing Research, 47(4), 764-776. doi: 10.1509/jmkr.47.4.764

Aiken, L. S., \& West, S. G. (1991). Multiple regression: testing and interpreting interactions. Newbury Park: Sage.

Anderson, E., \& Oliver, R. L. (1987). Perspectives on behavior-based versus outcome-based salesforce control systems. Journal of Marketing, 51(4), 76-88. doi: 10.2307/1251249

Atuahene-Gima, K. (1997). Adoption of new products by the sales force: the construct, research propositions and managerial implications. Journal of Product Innovation Management, 14(3), 435-450. doi: 10.1016/S0737-6782(97)00060-х 
Baldauf, A., Cravens, D. W., \& Wagner, U. (2000). Examining determinants of export performance in small open economies. Journal of World Business, 35(1), 61-79. doi: 10.1016/S10909516(99)00034-6

Basu, A. K., Lal, R., Srinivasan, V., \& Staelin, R. (1985). Sales force compensation plans: an agency theoretic perspective. Marketing Science, 4(4), 267-291. doi: 10.1287/mksc.4.4.267

Bergen, M., Dutta, S., \& Walker, O. C., Jr. (1992). Agency relationships in marketing: a review of the implications and applications of agency and related. Journal of Marketing, 56(3), 1-24. doi: $10.2307 / 1252293$

Boehe, D. M., Milan, G. S., \& De Toni, D. (2009). Desempenho do processo de desenvolvimento de novos produtos: o peso relativo de fatores organizacionais, mercadológicos e operacionais. Revista de Administração da Universidade de São Paulo RAUSP, 44(3), 250-254.

Brown, S. P., Evans, K., Mantrala, M., \& Challagalla, G. (2005). Adapting motivation, control, and compensation research to a new environment. Journal of Personal Selling \& Sales Management, 25(2), 155-167. doi: 10.1080/08853134.2005.10749056

Brown, S. P., \& Peterson, R. A. (1994). The effect of effort on sales performance and job satisfaction. Journal of Marketing, 58(2), 70-80. doi: 10.2307/1252270

Carson, S. J. (2007). When to give up control of outsourced new product development. Journal of Marketing, 7l(1), 49-66. doi: 10.1509/jmkg.71.1.49

Claro, D. P., \& Laban, S. A., Neto (2011). Social networks and sales performance. Revista de Administração Contemporânea, 15(3), 498-512. Recuperado de http://www.scielo.br/pdf/rac/v15n3/v15n3a08.pdf. doi: 10.1590/S1415-65552011000300008

Cohen, M. A., Eliashberg, J., \& Ho, T. H. (1997). An anatomy of a decision-support system for developing and launching line extensions. Journal of Marketing Research, 34(1), 117-129. doi: $10.2307 / 3152069$

Cravens, D. W., Ingram, T. N., LaForge, R. W., \& Young, C. E. (1993). Behavior-based and outcomebased salesforce control systems. Journal of Marketing, 57(4), 47-59. doi: 10.2307/1252218

Cravens, D. W., Lassk, F. G., Low, G. S., Marshall, G. W., \& Moncrief, W. C. (2004). Formal and informal management control combinations in sales organizations: the impact on salesperson consequences. Journal of Business Research, 57(3), 241-248. doi: 10.1016/S01482963(02)00322-3

Cron, W. L., \& Slocum, J. W., Jr. (1986). The influence of career stages on salespeople's job attitudes, work perceptions, and performance. Journal of Marketing Research, 23(2), 119-129. doi: $10.2307 / 3151659$

Echambadi, R., \& Hess, J. D. (2007). Mean-centering does not alleviate collinearity problems in moderated multiple regression models. Marketing Science, 26(3), 438-445. doi: $10.1287 / \mathrm{mksc} .1060 .0263$

Editora Abril. (2011, setembro 7). Parece milagre! Novo remédio faz emagrecer 7 a 12 quilos em cinco meses. E sem grandes efeitos colaterais [Capa]. Veja, 2233(36), Ano 44.

Eisenhardt, K. M. (1989). Agency theory: an assessment and review. Academy of Management Review, 14(1), 57-74. doi: 10.5465/AMR.1989.4279003

Fang, E., Evans, K. R., \& Landry, T. D. (2005). Control systems' effect on attributional processes and sales outcome: a cybernetic information-processing perspective. Journal of the Academy of Marketing Science, 33(4), 553-574. doi: 10.1177/0092070305275249 
Fu, F. Q., Jones, E., \& Bolander, W. (2008). Product innovativeness, customer newness, and new product performance: a time-lagged examination of the impact of salesperson selling intentions on new product performance. Journal of Personal Selling and Sales Management, 28(4), 351364. doi: 10.2753/PSS0885-3134280402

Gonçalves, C., Filho, Gonçalves, C. A., \& Pardini, D. J. (2008). O impacto da inovação e da gestão do conhecimento de marketing no desempenho de novos produtos no mercado. Revista de Administração e Inovação, 5(2), 5-24. doi: 10.5585/rai.v5i2.223

Hayes, A. F. (2013). An introduction to mediation, moderation, and conditional process analysis: a regression-based approach. New York: Guilford Press.

Homburg, C., Müller, M., \& Klarmann, M. (2011). When should the customer really be king? On the optimum level of salesperson customer orientation in sales encounters. Journal of Marketing, 75(2), 55-74. doi: 10.1509/jmkg.75.2.55

Hughes, D. E. (2013). This ad's for you: the indirect effect of advertising perceptions on salesperson effort and performance. Journal of the Academy of Marketing Science, 41(1), 1-18. doi: 10.1007/s11747-011-0293-y

Hultink, E. J., \& Atuahene-Gima, K. (2000). The effect of sales force adoption on new product selling performance. Journal of Product Innovation Management, 17(6), 435-450. doi: 10.1016/S07376782(00)00058-8

Kuster, I., \& Canales, P. (2011). Compensation and control sales policies, and sales performance: the field sales manager's points of view. Journal of Business and Industrial Marketing, 26(4), 273285. doi: $10.1108 / 08858621111127018$

Leão, A. L. M. S., \& Mello, S. C. B. (2010). Institucionalização como mecanismo de controle de Marketing. Revista de Administração Contemporânea, 14(2), 251-267. Recuperado de http://www.scielo.br/pdf/rac/v14n2/v14n2a05.pdf. doi: 10.1590/S1415-65552010000200005

Lindell, M. K., \& Brandt, C. J. (1999). Assessing interrater agreement on the job relevance of a test: a comparison of CVI, T, rWG (J)\}, and r* WG (J)\} indexes. Journal of Applied Psychology, 84(4), 640-645. doi: 10.1037/0021-9010.84.4.640

Mallin, M. L., \& Pullins, E. B. (2009). The moderating effect of control systems on the relationship between commission and salesperson intrinsic motivation in a customer oriented environment. Industrial Marketing Management, 38(7), 769-777. doi: 10.1016/j.indmarman.2008.03.004

Martins, F. R. (2006). Controle: perspectivas de análise na teoria das organizações. Cadernos EBAPE.BR, 4(1), 1-14. Recuperado de http://www.scielo.br/pdf/cebape/v4n1/v4n1a08.pdf. doi: $10.1590 /$ S $1679-39512006000100008$

Miao, C. F., \& Evans, K. R. (2012). Effects of formal sales control systems: a combinatory perspective. International Journal of Research in Marketing, 29(2), 181-191. doi: 10.1016/j.ijresmar.2011.09.002

Miao, C. F., \& Evans, K. R. (2013). The interactive effects of sales control systems on salesperson performance: a job demands-resources perspective. Journal of the Academy of Marketing Science, 4l(1), 73-90. doi: 10.1007/s11747-012-0315-4

Miao, C. F., \& Evans, K. R. (2014). Motivating industrial salesforce with sales control systems: an interactive perspective. Journal of Business Research, 67(6), 1233-1242. doi: 10.1016/j.jbusres.2013.04.007. 
Miao, C. F., Evans, K. R., \& Zou S. (2007). The role of salesperson motivation in sales control systems-Intrinsic and extrinsic motivation revisited. Journal of Business Research, 60(5), 417425. doi: 10.1016/j.jbusres.2006.12.005

Miao, C. F., Lund D. J., \& Evans, K. R. (2009). Re-examining the influence of career stages on salesperson motivation: a cognitive and affective perspective. Journal of Personal Selling \& Sales Management, 29(3), 243-255. doi: 10.2753/PSS0885-3134290303

Moreau, C. P., Lehmann, D. R., \& Markman, A. B. (2001). Entrenched knowledge structures and consumer response to new products. Journal of Marketing Research, 38(1), 14-29. doi: 10.1509/jmkr.38.1.14.18836

Nunnally, J. C. (2010). Psychometric theory. New York: McGraw-Hill Education.

Oliver, R. L., \& Anderson, E. (1994). An empirical test of the consequences of behavior- and outcomebased sales control systems. Journal of Marketing, 58(3), 53-67. doi: 10.2307/1251916

Oliver, R. L., \& Anderson, E. (1995). Behavior- and outcome-based sales control systems: evidence and consequences of pure-form and hybrid governance. Journal of Personal Selling \& Sales Management, 15(4), 1-15. doi: 10.1080/08853134.1995.10754033

Onyemah, V., \& Anderson, E. (2009). Inconsistencies among the constitutive elements of a sales force control system: test of a configuration theory-based performance prediction. Journal of Personal Selling \& Sales Management, 29(1), 9-24. doi: 10.2753/PSS0885-3134290101

Rangaswamy, A., Sinha, P., \& Zoltners, A. (1990). An integrated model-based approach for sales force structuring. Marketing Science, 9(4), 279-298. doi: 10.1287/mksc.9.4.279

Rapp, A., Ahearne, M., Mathieu, J., \& Schillewaert, N. (2006). The impact of knowledge and empowerment on working smart and working hard: the moderating role of experience. International Journal of Research in Marketing, 23(3), 279-293. doi: 10.1016/j.ijresmar.2006.02.003

Spiller, S. A., Fitzsimons, G. J., Lynch, J. G., Jr., \& McClelland, G. H. (2013). Spotlights, floodlights, and the magic number zero: simple effects tests in moderated regression. Journal of Marketing Research, 50(2), 277-288. doi: 10.1509/jmr.12.0420

Teddlie, C., \& Yu, F. (2007). Mixed methods sampling: a typology with examples. Journal of Mixed Methods Research, 1(1), 77-100. doi: 10.1177/2345678906292430

Van den Bulte, C., \& Lilien, G. L. (2001). Medical innovation revisited: social contagion versus marketing effort. American Journal of Sociology, 106(5), 1409-1435. doi: 10.1086/320819

Vieira, V. A., Galeano, R., \& Pires, D. (2013). Determinantes do desempenho empresarial e das vendas cruzadas no varejo. Revista de Administração de Empresas, 53(2), 565-579. doi: 10.1590/S003475902013005000003

Ward, T. B. (2004). Cognition, creativity, and entrepreneurship. Journal of Business Venturing, 19(2), 173-188. doi: 10.1016/S0883-9026(03)00005-3

Weitz, B. A. (1981). Effectiveness in sales interactions: a contingency framework. Journal of Marketing, 45(1), 85-103. doi: 10.2307/1251723

West, S. G., Aiken, L. S., \& Krull, J. L. (1996). Experimental personality designs: analyzing categorical by continuous variable interactions. Journal of Personality, 64(1), 1-48. doi: 10.1111/j.14676494.1996.tb00813.x 


\section{Dados dos Autores}

Valter Afonso Vieira

Av. Colombo, 5790, Bloco C23, 87020-900, Maringá, PR, Brasil. E-mail: valterafonsovieira@ gmail.com

Juliano Domingues silva

Av. Colombo, 5790, Bloco C23, 87020-900, Maringá, PR, Brasil. E-mail: juliannodomingues@ yahoo.com.br

Sean Cassiolato Berbert

Rua Imaculada Conceição, 1155, Sala 103b, Curitiba, PR, Brasil. E-mail: sean@ viagee.com.br

Valter da Silva Faia

Av. Colombo, 5790, Bloco C23, 87020-900, Maringá, PR, Brasil. E-mail: valterfaia@gmail.com 


\section{ANEXO}

\section{Informações das Variáveis}

\begin{tabular}{lcccccc}
\hline & Estudo 1 & \multicolumn{5}{c}{ Estudo 2 } \\
\cline { 2 - 7 } Variáveis & Média & Dev. Padrão & Alfa & Média & Dev. Padrão & Alfa \\
\hline Tempo de vendas & 8,91 & 7,46 & & 11,47 & 6,59 & \\
Tempo de empresa & 5,44 & 4,55 & & 7,56 & 5,47 & \\
Número de empregados & 7,00 & 3,39 & & & & \\
Tempo de vendas de veíc. & & & & 8,45 & 5,34 & \\
Inovação & 7,78 & 1,32 & 0,73 & 8,29 & 1,25 & 0,72 \\
Perc. Comissão (\%) & & & & 85,38 & 13,37 & \\
Percep. Qualidade da Inovação & 8,11 & 1,16 & 0,76 & 8,84 & 1,03 & 0,73 \\
Desempenho geral (estudo 1) & 8,60 & 1,21 & 0,79 & & & \\
Desempenho do produto (estudo 2) & & & & 7,41 & 1,57 & 0,68 \\
Sistema de controle (global) & 1,30 & 2,63 & & 1,35 & 1,65 & \\
Sistema por comportamento & 7,13 & 2,03 & 0,76 & 8,72 & 1,21 & 0,76 \\
Sistema por resultado & 5,82 & 2,35 & 0,76 & 8,37 & 1,52 & 0,61 \\
Esforço na venda do produto & 0,40 & 1,75 & 0,75 & 8,39 & 1,20 & 0,65 \\
Experiência com vendas & 7,59 & 1,42 & 0,85 & 8,77 & 1,03 & 0,81 \\
\hline
\end{tabular}

Nota. Espaço em branco não se aplica. 